\title{
Importance of wave and current exposure to fauna communities in Laminaria hyperborea kelp forests
}

\author{
K. M. Norderhaug ${ }^{1,2, *}$, H. Christie ${ }^{1}$, E. Rinde ${ }^{1}$, H. Gundersen ${ }^{1,2}$, T. Bekkby ${ }^{1,3}$ \\ ${ }^{1}$ Norwegian Institute for Water Research (NIVA), Gaustadalléen 21, 0349 Oslo, Norway \\ ${ }^{2}$ Department of Biology, University of Oslo, PO Box 1066, Blindern, 0316 Oslo, Norway \\ ${ }^{3}$ Natural History Museum, University of Oslo, PO Box 1172, Blindern, 0318 Oslo, Norway
}

\begin{abstract}
Hydrodynamic forces from waves and currents may have strong but different impacts on benthic diversity. In order to study the relative importance of current and wave exposure to the diversity of macrofauna associated with the kelp Laminaria hyperborea, we sampled fauna on epiphytic algae of 4 different morphological types from 27 stations in a crossed design with 3 levels of wave exposure and current speed. Fauna species number $(S)$ was determined by morphology and amount (weight) of epiphyte and the interaction between wave exposure and current speed. Shannon-Wiener diversity $H^{\prime}$ was determined by the epiphyte morphology and amount and degree of wave exposure. The most important factors for faunal community composition were epiphyte morphology and wave exposure, and the effect of wave exposure was different for algae of different morphology. The most diverse fauna communities were found at intermittently wave-exposed sites and on large, rough epiphytic algae. The study shows that waves and currents influence kelp fauna communities very differently. Within our study area, waves had a stronger overall effect compared to currents.
\end{abstract}

KEY WORDS: Kelp fauna · Diversity · Community composition · Hydrodynamic forces · Waves · Currents

Resale or republication not permitted without written consent of the publisher

\section{INTRODUCTION}

The importance of hydrodynamic forces in structuring marine communities has been recognized for decades (e.g. Brattström \& Matthews 1968). However, because wave and current forces are difficult to quantify in a consistent manner with respect to space and time, few attempts have been made to describe how biological communities respond to increasing levels of these forces. The Norwegian coast is highly influenced by waves and currents and includes areas with a large range in both of these forces. Tidal differences are large in mid-Norway and further north, and outer coastal areas are highly exposed to waves.
These 2 forces may act independently or they may interact in their influence on benthic organisms. For mobile organisms, waves and currents are physical disturbances that may increase the community diversity by stochastically removing specimens and therefore preventing superior competitors from outcompeting inferior ones (Begon et al. 1990). According to the intermediate disturbance hypothesis, medium levels may be expected to promote the highest diversity (Dial \& Roughgarden 1998).

The kelp Laminaria hyperborea dominates rocky sea beds along the Norwegian coastal areas with moderate to high levels of wave exposure (Kain 1967, Bekkby et al. 2009). A rich and abundant mobile 
macrofauna, dominated by crustaceans and gastropods, is associated with kelp, and the largest abundances are found in association with epiphytic algae on kelp stipes (Norderhaug et al. 2002). Wave forces may result in a considerable loss of fauna due to physical dislodgement from the kelp (Fincham 1974, Fenwick 1976). Wave exposure has also been found to increase diversity of macrofauna associated with epiphytic algae in kelp forests on the Norwegian coast (Christie et al. 2003, Norderhaug et al. 2012). Apart from a few single-species studies (e.g. GuerraGarcia 2002), the effects of currents on kelp macrofauna diversity have not been studied.

Hydrodynamic forces may influence benthic fauna communities indirectly by structuring their habitat, e.g. because of variation in the species composition of algae according to wave exposure level (Christie et al. 2003, Kraufvelin et al. 2010). Water flow increases algal growth by transporting nutrients across algal surfaces and causes drag forces that may dislodge algae. Diversity may correlate with primary production (Miki 2009) and habitat size (Anderson et al. 2005), until a species saturation is reached. The total amount of epiphytes on kelp stipes generally increases with wave exposure (Christie et al. 2003), and T. Bekkby unpubl. data show that this is also the case with increasing current speed. Morphology and the amount of epiphytic algae are important factors for the abundance and diversity of the associated macrofauna community. Epiphytic algae morphology and surface structure provide different habitat qualities and are used by different faunal species with respect to faunal size, body form and mobility (Hacker \& Steneck 1990, Gee \& Warwick 1994, Kraufvelin et al. 2002, Eilertsen et al. 2011). Kelp faunal abundances depend on both the amount of the habitat algae (Norderhaug et al. 2007) and algal morphology (Christie et al. 2007).

The main aim of this study was to test the relative importance of current speed and wave exposure for the diversity and composition of fauna communities associated with kelp. This was done by comparing number of species, diversity and community composition of macrofauna associated with epiphytic algae from sites with different levels of wave exposure and current speed. Recently developed models that quantify wave and current levels spatially provide the opportunity to analyse the responses of communities associated with kelp with respect to these 2 hydrodynamic forces and to the combined effects (the interaction).

\section{MATERIALS AND METHODS}

\section{Study area and sampling design}

The study was performed in the archipelago off the Møre coast (the West coast of Norway, $62^{\circ} \mathrm{N}$ ), an area with high wave exposure and strong tidal currents and with optimal growth conditions for kelp Laminaria hyperborea (Rinde \& Sjøtun 2005). The focus of the study was the mobile macrofauna associated with epiphytic red algae on kelp stipes. While algal species composition changes with exposure, the morphology of the host algae is most important for the associated faunal community structure. With the use of natural and artificial habitats, Christie et al. (2007) showed that the epiphytic algae could be classified into 4 morphological classes with uniform fauna communities (bushy, leaf, rough and smooth morphology). Consequently, 3 replicate samples of epiphytic algae on kelp from these 4 different morphology classes were sampled from 3 replicate stations and from all combinations of 3 different levels of wave and current exposure (low, medium and high; Table 1).

A total of 311 samples (12 missing samples) were collected from 27 stations (Fig. 1) in a crossed design. Epiphytic algae with the associated fauna were randomly sampled by SCUBA diving and were enclosed sepa-

Table 1. Average algal amount (measured as g wet weight [WW]), fauna species number $S$ (no. of species), fauna abundance (no. of ind.) and fauna diversity (Shannon-Wiener index $H^{\prime}$ ) from the different sampled epiphytic algae classified into morphology groups (bushy, leaf-shaped, rough and smooth algae) at different exposure levels. Exposure codes: w: wave exposure, c: current exposure; 1: low level, 2: medium level, 3: high level

\begin{tabular}{|c|c|c|c|c|c|c|c|c|c|}
\hline & w1c1 & w1c2 & w1c3 & $\mathrm{w} 2 \mathrm{c} 1$ & $\mathrm{w} 2 \mathrm{c} 2$ & $\mathrm{w} 2 \mathrm{c} 3$ & $\mathrm{w} 3 \mathrm{c} 1$ & w3c2 & w3c3 \\
\hline \multicolumn{10}{|c|}{ Algal weight } \\
\hline Bushy & 3.7 & 7.8 & 4.7 & 10.2 & 19.9 & 5.8 & 7.6 & 3.6 & 5.9 \\
\hline Leaf & 4.9 & 6.7 & 6.5 & 10.5 & 10.1 & 13.9 & 9.5 & 14.8 & 13.9 \\
\hline Rough & 3.7 & 11.2 & 13.3 & 13.5 & 13.6 & 15.9 & 12.1 & 17.3 & 16.4 \\
\hline Smooth & 0.73 & 2.5375 & 3.0 & 5.3 & 8.4 & 10.5 & 11.1 & 28.9 & 19.3 \\
\hline \multicolumn{10}{|c|}{ Fauna species number $S$} \\
\hline Bushy & 9.0 & 11.8 & 9.8 & 12.0 & 13.5 & 14.1 & 14.1 & 10.6 & 10.2 \\
\hline Leaf & 13.5 & 10.8 & 10.4 & 12.7 & 12.8 & 13.6 & 11.0 & 11.8 & 11.1 \\
\hline Rough & 11.5 & 14.1 & 8.25 & 11.1 & 16.5 & 12.8 & 13.7 & 14.6 & 12.4 \\
\hline Smooth & 13.2 & 9.8 & 12 & 10.7 & 11 & 12.5 & 13.3 & 14.1 & 14.4 \\
\hline \multicolumn{10}{|c|}{ Fauna abundance } \\
\hline Bushy & 63 & 75.1 & 153 & 64.3 & 137 & 126 & 65 & 41.8 & 44.2 \\
\hline Leaf & 151 & 156 & 150 & 532 & 483 & 569 & 199 & 529 & 603 \\
\hline Rough & 145 & 433 & 573 & 770 & 657 & 594 & 428 & 895 & 713 \\
\hline Smooth & 16 & 46.3 & 51 & 91 & 66.1 & 68.7 & 46.0 & 214 & 91.4 \\
\hline \multicolumn{10}{|c|}{ Fauna diversity $H^{\prime}$} \\
\hline Bushy & 1.90 & 1.83 & 1.74 & 1.63 & 2.00 & 1.47 & 1.72 & 1.82 & 1.67 \\
\hline Leaf & 1.76 & 2.11 & 1.99 & 1.73 & 1.71 & 1.34 & 1.72 & 1.77 & 1.70 \\
\hline Rough & 2.24 & 2.08 & 2.02 & 1.70 & 1.73 & 1.62 & 1.92 & 1.69 & 1.73 \\
\hline Smooth & 1.33 & 1.58 & 1.55 & 1.78 & 1.49 & 1.15 & 1.54 & 1.68 & 1.68 \\
\hline
\end{tabular}


a)

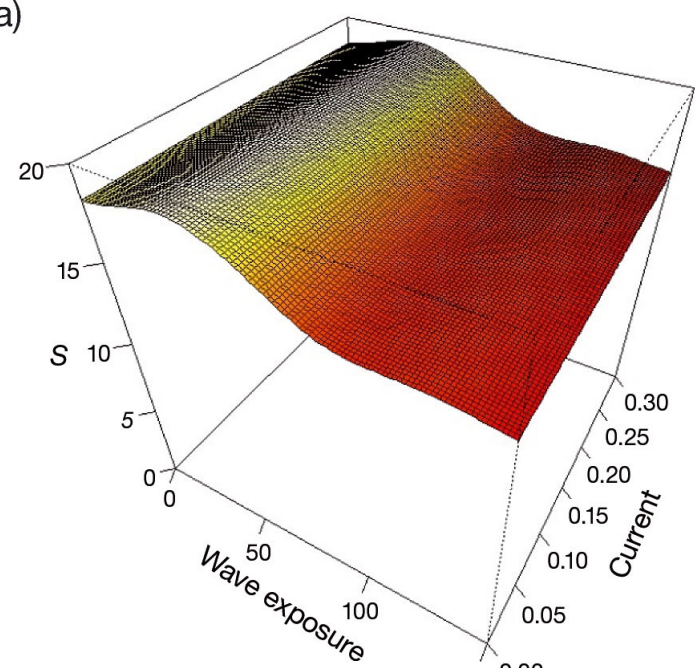

c)

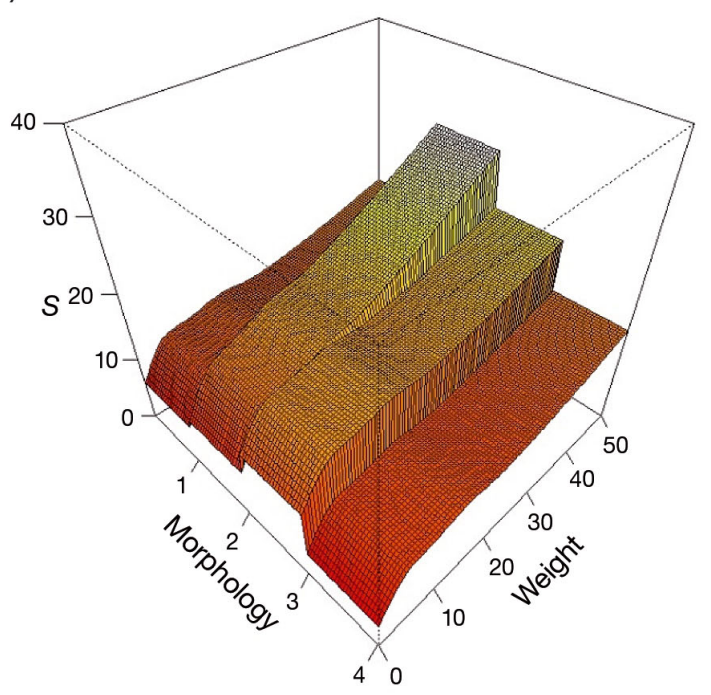

b)
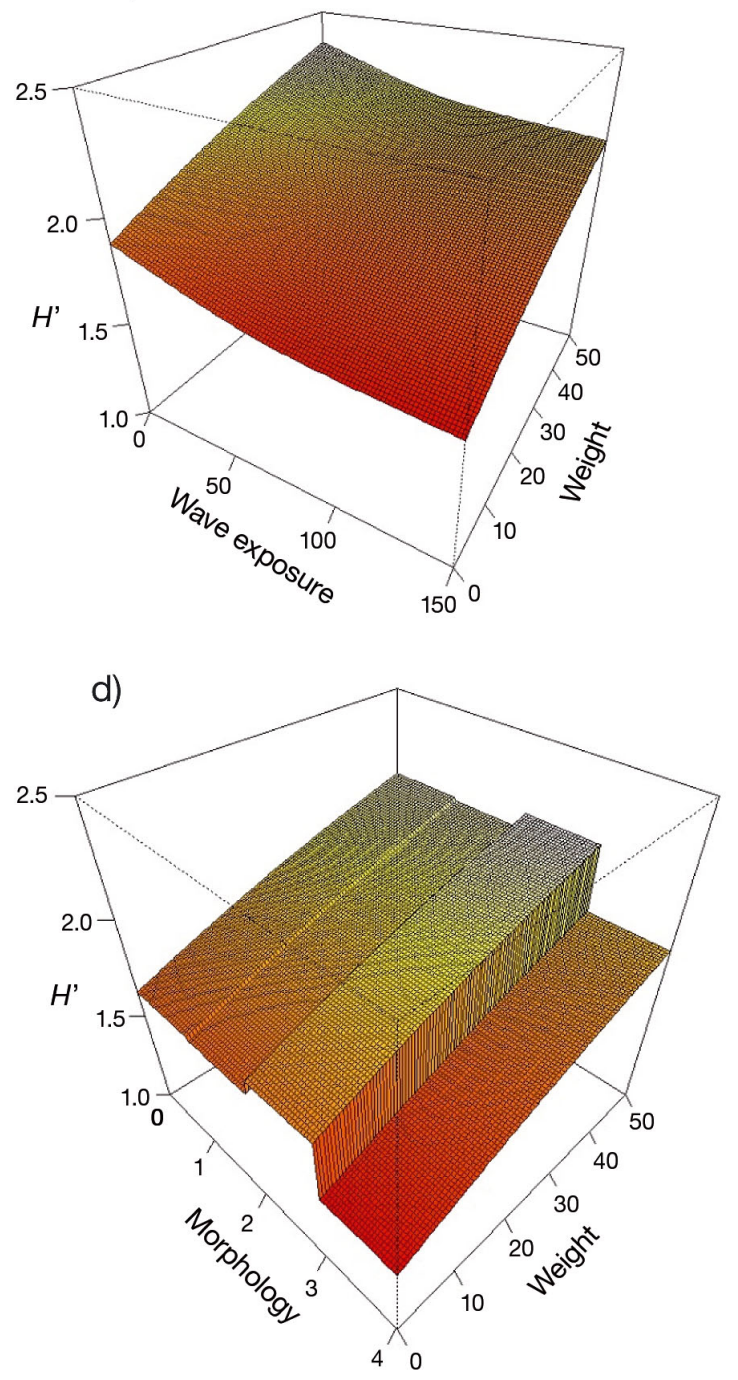

Fig. 1. Response plots of the averaged mixed generalized additive models for number of faunal species $S$ by (a) wave exposure and current speed and by (c) epiphyte amount (weight, $g$ ) for each morphology of the epiphyte $(1=$ bushy, $2=$ leaf, $3=$ rough, 4 = smooth), and for the Shannon-Wiener diversity index $H^{\prime}$ by (b) wave exposure and epiphyte amount (weight, g) and (d) morphology and epiphyte amount (weight, g)

rately in plastic bags underwater. The fauna collected in the bags were sieved (mesh size $250 \mu \mathrm{m}$ ). We excluded meiofauna (e.g. copepods, nematodes and oligochaetes) from the study, thereby including only the macrofauna in the analysis. For each sample, the habitat amount (wet weight) of the algae was measured. In the laboratory, the animals were counted and identified to species or the lowest possible taxonomic level.

\section{Modelled wave exposure and current level}

Wave exposure $\left(\mathrm{m}^{2} \mathrm{~s}^{-1}\right)$ was modeled with a spatial resolution of $10 \mathrm{~m}$ using data on fetch (distance to nearest shore, island or coast), wind speed and wind frequency within sectors (Isæus 2004). Data on wind speed and direction were delivered by the Norwegian Meteorological Institute and averaged over a 5 yr period just prior to the study period. The model has been applied to a number of research studies on kelp distribution (Bekkby et al. 2009, Bekkby \& Moy 2011), diversity (Norderhaug et al. 2012) and secondary production (Norderhaug et al. 2012) within the study area. The dominating winds in the area come from the south-southwest $\left(195-225^{\circ}\right)$. To reduce the difference in order of magnitude between wave and current exposure, estimated wave exposure values were divided by 10000 prior to statistical analysis. Low wave exposure level was between $5.0 \times 10^{4}$ and $3.9 \times 10^{5} \mathrm{~m}^{2} \mathrm{~s}^{-1}$, medium $5.2 \times 10^{5}$ and $9.0 \times 10^{5} \mathrm{~m}^{2} \mathrm{~s}^{-1}$ 
and high $10^{6}$ and $1.4 \times 10^{6} \mathrm{~m}^{2} \mathrm{~s}^{-1}$. The modelled wave exposure index has been shown to resemble the long-term average of significant wave height (using data from the Baltic Sea) and corresponds to waves between 0.1 and approximately $1.5 \mathrm{~m}$ high within the study area (Wijkmark \& Isæus 2010).

Current speed $\left(\mathrm{m} \mathrm{s}^{-1}\right)$ was estimated by the 3dimensional numerical ocean model ROMS (Shchepetkin \& McWilliams, 2005) in a multi-level nesting procedure. In the first level, ocean currents, atmospheric forcing (from the Norwegian Meteorological Institute, met.no) and climatological river flow rates (from the Norwegian Water Resources and Energy Directorate, NVE) drove an ocean model at a $500 \mathrm{~m}$ horizontal resolution. Fields from this model were used to drive a series of inner models, resulting in a model of $100 \mathrm{~m}$ horizontal resolution. We used mean values of the depth-averaged component of the model (averaged over the water column). Low current was between 0.01 and $0.09 \mathrm{~m} \mathrm{~s}^{-1}$, medium 0.12 and $0.18 \mathrm{~m} \mathrm{~s}^{-1}$ and high 0.20 and $0.47 \mathrm{~m} \mathrm{~s}^{-1}$.

\section{Statistical and numerical analysis}

To analyse the differences in macrofauna diversity (measured as number of species, $S$, and ShannonWiener diversity index, $H^{\prime}$; Hill 1973) with respect to waves and currents, we used the software $\mathrm{R}$ version 2.15.0 (R Development Core Team 2012) and mixed generalized additive models (GAMs) in the mgcv package (Wood 2004). Station was included as a random factor to control for potential non-independent variation between stations. The R package MuMIn (Barton 2012) was used for model selection and to estimate the relative importance of the different predictor variables. MuMIn calculates the chosen model selection criteria (i.e. corrected Akaike's information criterion $\left[\mathrm{AIC}_{\mathrm{c}}\right]$ values). We used $\Delta \mathrm{AIC}<4$ to identify the models that receive most support from the data (see Burnham et al. 2011). Morphology was included as a categorical factor with 4 levels (bushy, leaf, rough and smooth), whereas epiphytic algae wet weight (habitat amount), and wave and current exposure were included as continuous predictor variables. We used cubic regression spline as the penalized smoothing basis. To avoid overfitting, the dimension of the basis used to represent the smooth term $(k)$ was set to 3 for single predictors and to 6 for interactions. The 2D smooth interaction between wave exposure and current was included, as well as the interaction between morphology and weight of the epiphytic algae (i.e. habitat amount). We used restricted maximum likelihood estimation of smoothing parameters according to Lin \& Zhang (1999). MuMIn calculates relative importance of the predictors as the sum of Akaike weights over all models including the explanatory variable, among the selected subset of models (i.e. models with $\triangle \mathrm{AIC}<4$; Barton 2012). The check for concurvity, the nonparametric analogue of collinearity between explanatory factors (Ramsay et al. 2003), revealed that the predictors were sufficiently uncorrelated with concurvity indices between 0.03 and 0.31 (pairwise tests of the type 'estimate' in $\mathrm{mgcv}$ ). These measures lie well below worrying levels of dependency between covariates, and thus there is little chance of underestimated variance of fitted model parameters (Ramsay et al. 2003) or convergence failure (Wood 2008). Regardless, these 2 issues would not be of major importance in our study since (1) we used model selection by information-theoretic methods (AIC) and not p-values for model selection, and (2) all candidate models actually converged properly.

To analyse for differences in the community composition of animals between samples, we used permutational ANOVA (PERMANOVA) (Anderson 2001) in the PRIMER 6.0 computer package. The number of individuals per algae of each fauna species was calculated and square root-transformed before used in the analyses. Wave exposure (3 levels), current speed (3 levels) and morphology (4 levels) were used as fixed factors and interactions were included. Station was included as a random variable to control for potential non-independent variation between stations and was nested in wave exposure $\times$ current speed. Epiphytic algae wet weight was used as a covariate to control for the obvious effect of epiphyte amount (see Anderson et al. 2005).

\section{RESULTS}

Altogether, 86956 fauna specimens were identified. In Table 1, the species number and diversity (measured as $S$ and $H^{\prime}$, respectively) of fauna associated with the 4 different morphological classes of epiphytic algae are shown. Bushy algae included species in the genera Ceramium, Desmarestia, Ectocarpus, Heterosiphonia, Polysiphonia and Trillaella. Leaf-shaped algae included species in the genera Delesseria, Odontalia and Phycodrus. Rough algae included species in the genera Membranoptera, Ptilota and Rhodomela. Smooth algae included species in the genera Callophyllis, Laminaria (juvenile) and Palmaria. The highest abundances of fauna were found on leaf-shaped and rough algae. 


\section{Faunal diversity}

Summary statistics of the best mixed GAMs for explaining fauna diversity ( $S$ and $H^{\prime}$, according to $\mathrm{AIC}_{\mathrm{c}}$ values) are provided in Table 2. The species number, $S$, was determined by epiphyte morphology, epiphyte amount (algal wet weight), the interaction between these 2 factors and the interaction between wave exposure and current speed (Table 2A). Shannon-Wiener diversity, $H^{\prime}$, was determined by epiphyte morphology, epiphyte amount (algal wet weight) and wave exposure level (Table 2B). Current speed did not provide a significant contribution to the model for $H^{\prime}$.

Fig. 1 shows the partial effects of waves, currents, epiphyte weight and epiphyte morphology for the averaged models of $S$ and $H^{\prime}$. The effects on $S$ from waves and currents were not linear. Rather, intermediate levels of waves were associated with the highest $S$, while $S$ decreased when both waves and currents were high. $S$ showed a greater variation in the response to waves than to currents. $H^{\prime}$ decreased slightly with increasing wave exposure level. The highest values of $S$ and $H^{\prime}$ were found on algae with rough morphology. $S$ was higher on leaf-shaped algae than bushy or smooth algae. Smooth algae housed the lowest species diversity ( $S$ and $H^{\prime}$ were both low).

\section{Faunal community composition}

According to PERMANOVA, the fauna community differed significantly with epiphyte amount (algal wet weight), epiphyte morphology and wave exposure level (Table 3). There were also significant local differences between sampling stations. There were no significant community differences identified according to current speed.

\section{DISCUSSION}

The most important factors driving the observed differences in kelp fauna diversity ( $S$ and $H^{\prime}$ ) were: habitat morphology, habitat amount (algal weight) and wave exposure (the interaction between wave and current exposure in the case of $S$ ). $S$ was highest at intermediate wave exposure levels while $H^{\prime}$ decreased slightly, but significantly, with increasing wave exposure level. Hence the most diverse kelp fauna communities with respect to $S$ and an even distribution between species (high $H^{\prime}$ ) were found at intermediate wave-exposed sites. The analysis im-
Table 2. Summary statistics of the best mixed generalized additive model according to the corrected Akaike's information criterion value for explaining (a) the number of macrofauna species $S\left(\mathrm{R}^{2}{ }_{\text {adj }}=0.568\right.$, scale estimate $=10.504, \mathrm{n}=$ $311)$ and (b) the Shannon-Wiener diversity index $H^{\prime}\left(\mathrm{R}^{2}\right.$ adj $=$ 0.149 , scale estimate $=0.125, \mathrm{n}=311$ ) using wave exposure (wave), current speed (current), epiphytic weight/sample size (weight) and epiphyte morphology (with 4 levels: smooth, leaflike, bushy and rough) as explanatory variables. edf: estimated degrees of freedom

\begin{tabular}{|c|c|c|c|}
\hline (a) Best model of $S$ & Estimate (SE) & $t$ & $\mathrm{p}$ \\
\hline Intercept & $11.16(0.50)$ & 22.47 & $<0.001$ \\
\hline Leaf & $3.55(0.55)$ & 6.41 & $<0.001$ \\
\hline Rough & $4.63(0.57)$ & 8.09 & $<0.001$ \\
\hline Smooth & $-2.22(0.57)$ & -3.90 & $<0.001$ \\
\hline $\begin{array}{l}\text { Approximate significance } \\
\text { of smooth terms }\end{array}$ & edf & $F$ & $\mathrm{p}$ \\
\hline Wave $\times$ Current & 4.803 & 5.459 & $<0.001$ \\
\hline Weight & 4.397 & 5.885 & $<0.001$ \\
\hline Weight $\times$ Bushy & 1.042 & 0.008 & 0.9300 \\
\hline Weight $\times$ Leaf & 1.050 & 0.035 & 0.8636 \\
\hline Weight $\times$ Rough & 1.018 & 0.007 & 0.9350 \\
\hline Weight $\times$ Smooth & 1.020 & 0.006 & 0.9397 \\
\hline (b) Best model of $H^{\prime}$ & Estimate (SE) & $t$ & $\mathrm{p}$ \\
\hline Intercept & $1.78(0.052)$ & 33.8 & $<0.001$ \\
\hline Leaf & $-0.012(0.057)$ & -0.226 & 0.82 \\
\hline Rough & $0.062(0.059)$ & 1.05 & 0.29 \\
\hline Smooth & $-0.250(0.059)$ & -4.24 & $<0.001$ \\
\hline $\begin{array}{l}\text { Approximate significance } \\
\text { of smooth terms }\end{array}$ & edf & $F$ & $\mathrm{p}$ \\
\hline Weight & 1.327 & 13.7 & $<0.001$ \\
\hline Wave & 1.361 & 6.83 & 0.004 \\
\hline
\end{tabular}

plied that waves had a greater influence than currents on fauna diversity. The most important factors explaining differences in the community composition were (according to PERMANOVA) habitat morphology, habitat amount, wave exposure and the interaction between morphology and wave exposure. According to Denny (1985), hydrodynamic forces acting on benthos depend on the size and form of the organism, and the significant interaction between waves and algal morphology may have been attributed to differences in the effects that waves impose on different algae as shelter to fauna. There was also some unexplained local variation between the stations. Current speed alone had no significant influence. Thus, while GAMs showed a significant increase in the $S$ from currents at low wave exposure levels (interaction between exposure and current), the interaction was not significant in PERMANOVA. This shows that 
Table 3. Results of PERMANOVA using wave exposure (3 levels), current speed (3 levels) and algal morphology (4 levels: smooth, leaflike, bushy and rough) as fixed factors, station as a random factor and algal amount (weight, $g$ wet weight) as a covariate to analyse effects on the fauna community. Interactions between factors were included and station was nested within wave exposure and current speed. Data were square root transformed. Pseudo-F:

Fisher's test statistic

\begin{tabular}{|lrcccr|}
\hline Factor & df & SS & MS & Pseudo- $F$ & p \\
\hline Weight & 1 & 60859 & 60859 & 28.2 & 0.001 \\
Morphology & 3 & 87595 & 29198 & 14.4 & 0.001 \\
Wave & 2 & 44008 & 22004 & 4.5 & 0.001 \\
Current & 2 & 10250 & 5125 & 1.03 & 0.41 \\
Morphology $\times$ Wave & 6 & 27506 & 4584 & 2.37 & 0.001 \\
Morphology $\times$ Current & 6 & 12275 & 2045 & 1.08 & 0.26 \\
Wave $\times$ Current & 4 & 15075 & 3768 & 0.76 & 0.83 \\
Station (Wave $\times$ Current) & 20 & 91954 & 4597 & 4.2 & 0.001 \\
Morphology $\times$ Wave $\times$ & 12 & 20133 & 1677 & 0.94 & 0.65 \\
$\quad$ Current & & & & & \\
Morphology $\times$ Station & 53 & 93034 & 1755 & 1.62 & 0.001 \\
$\quad$ Wave $\times$ Current) & & & & & \\
Residuals & 201 & $2.17 \times 10^{5}$ & 1080 & & \\
Total & 310 & $6.79 \times 10^{5}$ & & & \\
\hline
\end{tabular}

levels of productivity (Rosenzweig 1995). Such production-diversity models are dimensionless; thus it is difficult to interpret according to our data. It is noteworthy that the primary production increases according to wave exposure level (Pedersen et al. 2012) and current level (T. Bekkby et al. unpubl. data), although the main food source of the fauna is fragmented kelp, which is in excess throughout kelp forests at different exposure levels (Norderhaug et al. 2003, 2012). Nevertheless, we cannot rule out the effect of production.

Habitat morphology strongly affected kelp fauna diversity and community structure. The interaction between morphology and exposure also shows that the effect from waves on the fauna depends on the

while $S$ increases with current (at low exposure), it is arbitrary and unsystematic in influencing the responses of individual species.

The observed differences in the influence of wave and current forces may have been attributed to their different hydrodynamic properties. Because waves break, effects from waves may impose larger community effects than currents. If waves produce stronger hydrodynamic forces on the benthos, the disturbing effects may be larger and result in a higher impact on diversity and community structure. Waves vary considerably in space and time with respect to direction, intensity and longevity, while currents in the study area are mainly tide-induced unidirectional flows. Thus, hydrodynamic wave forces are probably less predictable than current forces and may have a larger impact on community diversity (see Poff et al. 1997).

The humped response curve of $S$ to wave exposure and current speed can be explained by the intermediate disturbance hypothesis (Dial \& Roughgarden 1998), which states that local species diversity is maximized when ecological disturbance is neither too rare nor too frequent. Then moderately wave-exposed areas may experience a level of disturbance where both strong and weak competitor species can coexist. Another possible factor is related to production. In many systems, the relationship between primary productivity and diversity has been shown to be unimodal or hump-shaped, implying that diversity is highest at intermediate algal habitat and shows the importance of microhabitat properties for the inhabiting fauna community. Animals cling to or use the interstitial space between the fronds as habitat. Algal morphology determines the value of the algae as a habitat and differs for animals according to their size and shape (Hacker \& Steneck 1990). Suitable habitat may be a limited resource for the animals and variation in algal microstructure causes niche segregation. For example, slender and slow-moving caprellids cling to threadlike (bushy) algae (Guerra-Garcia 2002), while small and fast-swimming Ischoyroceridae utilize any habitat (Norderhaug et al. 2002), and gastropods crawl on smooth algal surfaces (Toth \& Pavia 2002).

In conclusion, our study shows that waves and currents are important for the diversity and composition of kelp forest fauna, but that these hydrodynamic forces may act very different on benthic communities. The largest effect on faunal diversity and composition was nevertheless, in accordance with earlier findings, habitat amount (Norderhaug et al. 2007), habitat morphology (Hacker \& Steneck 1990) and wave exposure (Norderhaug et al. 2012).

Acknowledgements. This study was a part of the research project KelpPredict. We are grateful to The Norwegian Research Council for funding, to Janne K. Gitmark for help with taxonomical analysis, to Kamil Barton for help with the MuMIn statistics and to Kate Hawley for correction of the manuscript. 


\section{LITERATURE CITED}

Anderson MJ (2001) A new method for non-parametric multivariate analysis of variance. J Ecol 26:32-46

- Anderson MJ, Diebelb CE, Blomb WM, Landers TJ (2005) Consistency and variation in kelp holdfast assemblages: spatial patterns of biodiversity for the major phyla at different taxonomic resolutions. J Exp Mar Biol Ecol 320: 35-56

Barton K (2012) MuMIn: Multi-model inference R package version 177. Available at: http://CRAN.R-project.org/ package $=$ MuMIn

Begon M, Harper JL, Townsend CR (1990) Ecology: individuals, populations and communities. Blackwell Scientific Publications, Oxford

> Bekkby T, Moy F (2011) Developing spatial models of sugar kelp (Saccharina latissima) potential distribution under natural conditions and areas of its disappearance in Skagerrak. Estuar Coast Shelf Sci 95:477-483

Bekkby T, Rinde E, Erikstad L, Bakkestuen V (2009) Spatial predictive distribution modelling of the kelp species Laminaria hyperborea. ICES J Mar Sci 66:2106-2115

Brattström H, Matthews JBL (1968) The importance of water movements for biology and distribution of marine organisms. 2nd Eur Symp Mar Biol. Sarsia 34:9-12

Burnham KP, Anderson DR, Huyvaert K (2011) AIC model selection and multimodel inference in behavioral ecology: some background observations and comparisons. Behav Ecol Sociobiol 65:23-35

> Christie H, Jørgensen NM, Norderhaug KM, WaageNielsen E (2003) Species distribution and habitat exploitation of fauna associated with kelp (Laminaria hyperborea) along the Norwegian coast. J Mar Biol Assoc UK 83:687-699

Christie H, Jørgensen NM, Norderhaug KM (2007) Bushy or smooth high or low; importance of habitat architecture and vertical position for distribution of fauna on kelp. J Sea Res 58:198-208

> Denny MW (1985) Wave forces on intertidal organisms: a case study. Limnol Oceanogr 30:1171-1187

- Dial R, Roughgarden J (1998) Theory of marine communities: the intermediate disturbance hypothesis. Ecology 79:1412-1424

Eilertsen M, Norderhaug KM, Sjøtun K (2011) Does the composition of amphipods associated to epiphytes on kelp (Laminaria hyperborea) change with depth? Mar Biol Res 7:224-234

> Fenwick GD (1976) The effect of wave exposure on the amphipod fauna of the algae Caulerpa brownii. J Exp Mar Biol Ecol 25:1-18

Fincham AA (1974) Periodic swimming behaviour of amphipods in Wellington Harbour New Zealand. J Mar Freshw Res 8:505-521

- Gee JM, Warwick RM (1994) Metazoan community structure in relation the fractal dimensions of marine macroalgae. Mar Ecol Prog Ser 103:141-150

Guerra-Garcia JM (2002) Re-descriptions of Caprella linearis (Linneaus 1767) and C. septentrionalis Kroyer 1838 (Crustacea: Amphipoda: Caprellidea) from Scotland with an ontogenetic comparison between the species and a study of the clinging behavior. Sarsia 87:216-235

- Hacker SD, Steneck RS (1990) Habitat architecture and the abundance and body-size-dependent habitat selection of a phytal amphipod. Ecology 71:2269-2285

- Hill MO (1973) Diversity and evenness: a unifying notation and its consequences. Ecology 54:427-432
Isæus M (2004) Factors structuring Fucus communities at open and complex coastlines in the Baltic Sea. PhD thesis, Department of Botany, Stockholm University

> Kain J (1967) Populations of Laminaria hyperborea at various latitudes. Helgol Wiss Meeresunters 15:489-499

> Kraufvelin P, Christie H, Olsen M (2002) Littoral macrofauna (secondary) responses to experimental nutrient addition to rocky shore mesocosms and a coastal lagoon. Hydrobiologia 484:149-166

Kraufvelin P, Lindholm A, Pedersen MF, Kirkerud LA, Bonsdorff E (2010) Biomass, diversity and production of rocky shore macroalgae at two nutrient enrichment and wave action levels. Mar Biol 157:29-47

Lin X, Zhang D (1999) Inference in generalized additive mixed models using smoothing splines. J R Stat Soc B 61: $381-400$

Miki T (2009) A new geographical model for untangling complex relationships among environment biodiversity and ecosystem functioning. Ecol Res 24:937-941

Norderhaug KM, Christie H, Rinde E (2002) Colonisation of kelp imitations by epiphyte and holdfast fauna; a study of mobility patterns. Mar Biol 141:965-973

Norderhaug KM, Fredriksen S, Nygaard K (2003) Trophic importance of Laminaria hyperborea to kelp forest consumers and the importance of bacterial degradation to food quality. Mar Ecol Prog Ser 255:135-144

> Norderhaug KM, Christie H, Fredriksen S (2007) Is habitat size an important factor for faunal abundances on kelp (Laminaria hyperborea)? J Sea Res 58:120-124

- Norderhaug KM, Christie H, Andersen GS, Bekkby T (2012) Does the diversity of kelp forest macrofauna increase with wave exposure? J Sea Res 69:36-42

Pedersen MF, Nejrup LB, Fredriksen S, Christie H, Norderhaug KM (2012) Effects of wave exposure on population structure, demography, biomass and productivity of the kelp Laminaria hyperborea. Mar Ecol Prog Ser 451: 45-60

$>$ Poff NL, Allan D, Bain MB, Karr JR and others (1997) The natural flow regime. Bioscience 47:769-784

R Development Core Team (2012) R: A language and environment for statistical computing $\mathrm{R}$ Foundation for Statistical Computing, Vienna, Austria. Available at: http: //www.R-project.org

Ramsay TO, Burnett RT, Krewski D (2003) The effect of concurvity in generalized additive models linking mortality to ambient particulate matter. Epidemiology 14:18-23

> Rinde E, Sjøtun K (2005) Demographic variation in the kelp Laminaria hyperborea along a latitudinal gradient. Mar Biol 146:1051-1062

Rosenzweig ML (1995) Species diversity in space and time. Cambridge University Press, New York, NY

$>$ Shchepetkin AF, McWilliams JC (2005) Regional ocean model system: a split-explicit ocean model with a free surface and topography-following vertical coordinate. Ocean Model 9:347-404

> Toth GB, Pavia H (2002) Intraplant habitat and feeding preference of two gastropod herbivores inhabiting the kelp Laminaria hyperborea. J Mar Biol Assoc UK 82:243-247

Wijkmark N, Isæus M (2010) Wave exposure calculations for the Baltic Sea. AquaBiota Report 2010:02

> Wood SN (2004) Stable and efficient multiple smoothing parameter estimation for generalized additive models. J Am Stat Assoc 99:673-686

Wood SN (2008) Fast stable direct fitting and smoothness selection for generalized additive models. J R Stat Soc B 70:495-518

Submitted: March 13, 2013; Accepted: February 2, 2014

Proofs received from author(s): April 7, 2014 